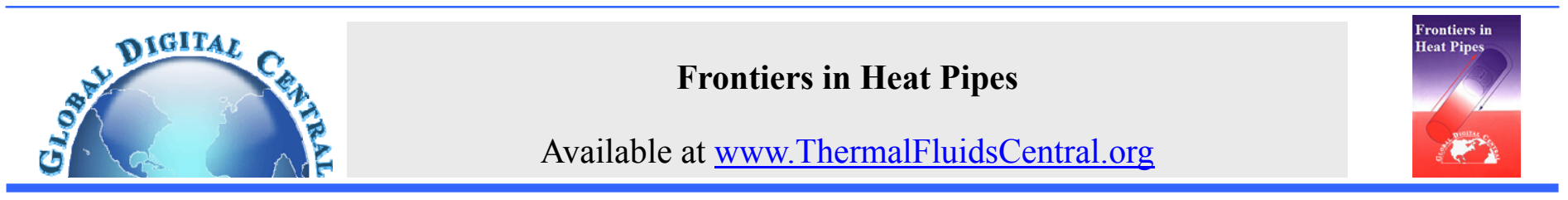

\title{
TRANSIENT MODELING OF HYBRID LOOP HEAT PIPE SYSTEMS WITH MULTIPLE EVAPORATORS
}

\author{
Dmitry Khrustalev $^{*}$ and Peter Cologer
}

ATK Space, Beltsville, MD, 20705, USA

\begin{abstract}
Hybrid Loop Heat Pipe Systems (HLHPS) are next-generation Loop Heat Pipe-type systems with multiple evaporators and only one reservoir colocated with a small secondary evaporator. HLHPS are capable of temperature-controlling heat sources distributed across the application system volume. In addition to multiple evaporators, HLHPS provide such benefits as compact packaging and high power and high heat flux levels compared to other capillary thermal control systems. This paper presents a transient model of a HLHPS with eight (8) main evaporators developed on the Thermal Desktop ${ }^{\mathrm{TM}}$ platform. The modeling results explain how these eight evaporators, cooling heat-dissipating components, can be kept inside a certain temperature range and provide general understanding of HLHPS transient operational regimes.

Keywords: Two-phase; temperature control; capillary wick.
\end{abstract}

\section{INTRODUCTION}

Hybrid Loop Heat Pipe System (HLHPS) is an advanced nextgeneration Loop Heat Pipe system with multiple main evaporators and one small secondary evaporator adjacent to the only reservoir in the system. HLHPS operational concepts are introduced by US Patents $6,889,754$ and 7,004,240. It is a "hybrid" in the sense of combining the best features typical for Loop Heat Pipes (LHPs) and Capillary Pumped Loops (CPLs). A HLHPS and a CPL with multiple evaporators have only one reservoir, which contains two-phase working fluid (liquid and saturated vapor). A HLHPS reservoir is hydraulically linked to the secondary evaporator with a secondary wick, similar to LHPs. This allows HLHPS to withstand severe fluid transients and tolerate vapor phase in the liquid flow returning to the reservoir from the condenser. The secondary evaporator with reservoir also provides for continuous sweepage liquid flow through the liquid cores of the main evaporators. The HLHPS operational concepts were described previously to a certain extent, for example by Bugby (2007) and by Wrenn and Wolf (2008), and are re-introduced below for the specific HLPS configuration modeled and presented in this paper.

The HLHPS reported by Wrenn and Wolf (2008) and also by Bugby (2007) performed very well during experimental testing within the operating range of the system. One objective of this paper is understanding through modeling the thermal-fluid mechanisms which bound the performance envelope for HLHPS, such as operating under transients induced by the heat load variations. Such understanding is useful for designing reliable HLHPS. Another objective of this paper is to present an effective modeling approach itself, using a commercial software package (Thermal Desktop ${ }^{\mathrm{TM}}$ ) capable of describing basic capillary devices, two-phase flows, and corresponding heat transfer mechanisms. The numerical modeling presented in this paper heavily utilizes the technical concepts discussed in the literature on LHPs.

\section{HLHPS OPERATIONAL PRINCIPLES}

A HLHPS schematic is provided by Fig. 1. Several main capillary evaporators acquire thermal energy from the heat dissipating components by vaporizing the working fluid at the interface between the porous primary wick and heated evaporator wall. Due to the capillary pressure developed by liquid-vapor meniscii in the primary wick, the vapor flows through the vapor transport line into the condenser bonded to the condenser plate, which is cooled by a heat sink. The liquid coming out of the condenser returns to the inner cores of the main evaporators and filters through the porous wick structure to its outer surface with the mass flow rate corresponding to that of the vapor flow. The liquid return is directed into the inner evaporator core through a small diameter tubing, which assists any possible vapor bubbles in the inner core to come out of the evaporator. The main evaporators can be plumbed either in parallel or in series via the liquid supply. Main evaporators in Figure 1 are connected in series in the sense that the liquid coming out of the condenser flows to the first evaporator, where it is only partially consumed due to the vaporization on the outer surface of the primary wick, while the rest of the liquid comes out of the first evaporator core and flows into the second evaporator core and subsequently into the next evaporator core. Highpower HLHPS with multiple evaporators would benefit from configuring main evaporators in parallel via the liquid supply. The distinguishing feature of a HLHPS is that there is fluid flow coming out of the last main evaporator core, usually called "sweepage flow" in the literature. Its important function is to sweep any possible vapor bubbles out of the liquid cores of the evaporators. This sweepage flow is created by heat loading a small secondary evaporator, constructed similarly to LHP evaporators, which generates some additional vapor flow into the condenser which continues as additional liquid flow exiting the condenser. The sweepage flow passes through all the evaporator cores along with the evaporating liquid feed, and ultimately exits from the last main evaporator and enters the subcooler shown in Fig. 1 adjacent

\footnotetext{
*Corresponding author Email: Dmitry.Khrustalev@ATK.com
} 
to the condenser plate. The liquid coming out of the subcooler flows into the inner core of the secondary evaporator, which is hydraulically coupled to the fluid inside the reservoir via a secondary wick, thereby completing the sweepage loop. The HLHPS major operational principles can be briefly summarized as follows:

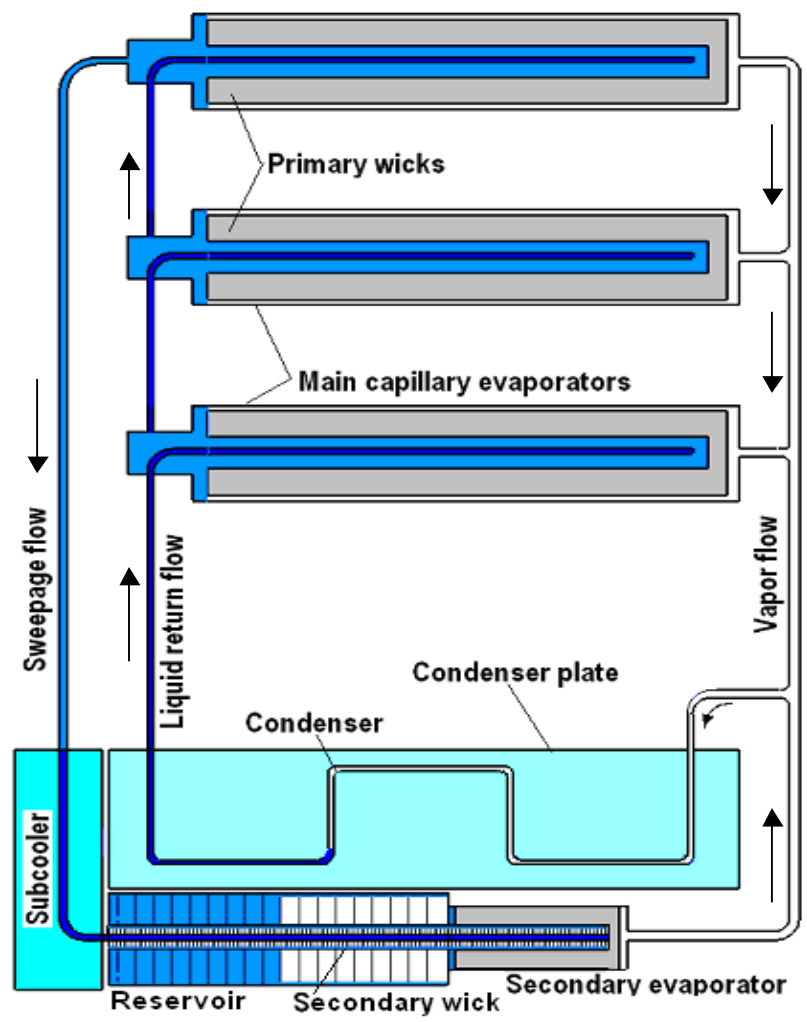

Fig. 1 HLHPS schematic with three main in-series evaporators

1. The HLHPS reservoir contains both liquid and vapor phases of the working fluid and, being the largest volume component, virtually dictates the level of the absolute pressure inside HLHPS.

2. The capillary pressure developed by the primary wicks provides the phase control and self-regulation in the system allowing the main evaporators to be subjected to different powers, locations (or distances), and elevations (in gravity), within the limits of the maximum capillary potential.

3. The secondary evaporator is always kept heat loaded, especially prior to heat loading of the main evaporators, so that the liquid flow through the liquid core of the main evaporators ensures the primary wicks are fully saturated with liquid and thus ready to be powered.

4. The liquid coming out of the condenser and flowing into the evaporator inner cores should be single-phase liquid preferably subcooled versus the saturation temperature in order to provide advantageous conditions for the main evaporators to be fully saturated with liquid and operating in the most reliable mode.

5. To guarantee reliable performance under severe transient conditions, it is desirable (although not always necessary) for HLHPS to be operated inside the design parameters envelope where the sweepage flow coming out of the last main evaporator and into the subcooler is a single-phase liquid.
6. Applying some minor heat load to the reservoir elevates the vapor temperature in HLHPs, which results in a shorter condensation length and colder liquid coming out of the condenser thus helping to avoid vapor phase in the liquid return line and the sweepage flow.

7. Powering small heaters on the liquid return lines during the time when the heat load on the main evaporators is zero but the secondary evaporator is heat loaded can be useful to prevent the main evaporators temperatures from dropping to the sink temperature.

The HLHPS operational principles above are based on observations derived from the experimental HLHPS testing discussed below.

\section{Recently Demonstrated Experimental HLHPS}

Wrenn and Wolf (2008) tested a 10-kilowatt ammonia system with six evaporators operated in a passive capillary-controlled mode where a secondary evaporator provided the sweepage flow through the primary evaporators. The system used 9"-long evaporators with metallic wicks. The evaporators were plumbed in series via the liquid supply. More than 50 tests were performed with a variety of elevations of the evaporators above (and below) the condenser plates. The system operated reliably during rapid power cycling transients and with nonuniform evaporator heat load in all tested orientations. The power on each evaporator was cycled from $1000 \mathrm{~W}$ to $100 \mathrm{~W}$ to $1000 \mathrm{~W}$ with the sweepage power of $50 \mathrm{~W}$. Vapor phase was observed in the sweepage flow in many tests. The measured pressure drops and temperature distributions in the system were compared to and matched the predictions generated by a steady state Thermal Desktop ${ }^{\mathrm{TM}}$ model.

Bugby (2007) reported testing of an ammonia HLHPS with four parallel miniaturized evaporators with porous Teflon wicks $6.4 \mathrm{~mm}$ outer diameter. The HLHPS withstood power cycling from $200 \mathrm{~W}$ to 50 $\mathrm{W}$ to $200 \mathrm{~W}$ and operated reliably with the heat flux of up to $30 \mathrm{~W} / \mathrm{cm}^{2}$ on the evaporator wall during 21 various tests. One major benefit of using porous Teflon as a material for the primary wicks is that it has a very low conductivity (versus a metallic wick) and, consequently, a low heat leak across the primary wick from its outer vapor side to the liquid in the inner core. A picture of the evaporator is shown in Fig. 2. Note that all fluid ports are located on one end of this particular evaporator design, which can be convenient for integration into tight-packaging assemblies. Another evaporator design with a metallic wick and all fluid ports lined up on one side of the evaporator, which makes all other sides available for interfacing with cooled components, is offered by US Patent 7,661,464. Two such evaporators were tested in a pumped two-phase system with $55 \mathrm{~W} / \mathrm{cm}^{2}$ on the evaporator wall (Khrustalev, et al. 2008). Images of the modeled HLHPS with eight main evaporators are provided in Figs. 3 and 4. Figure 3 is a 2D CAD image that allows one to trace the direction of the fluid flow in the transport lines. Figure 4 is a 3D Thermal Desktop ${ }^{\mathrm{TM}}$-generated image of the thermal-fluid model that produced the numerical results presented in this paper. The HLHPS configuration in Fig. 3 uses a serpentine smooth-wall condenser tubing soldered to the aluminum condenser plate, which is cooled by a heat sink, for example by a cold plate bolted to the condenser plate with a thermal interface material. The subcooler line is located at the end of the same condenser plate. The reservoir usually has a thermal link or strap to a colder component and an electrical heater to regulate its temperature as desired. 


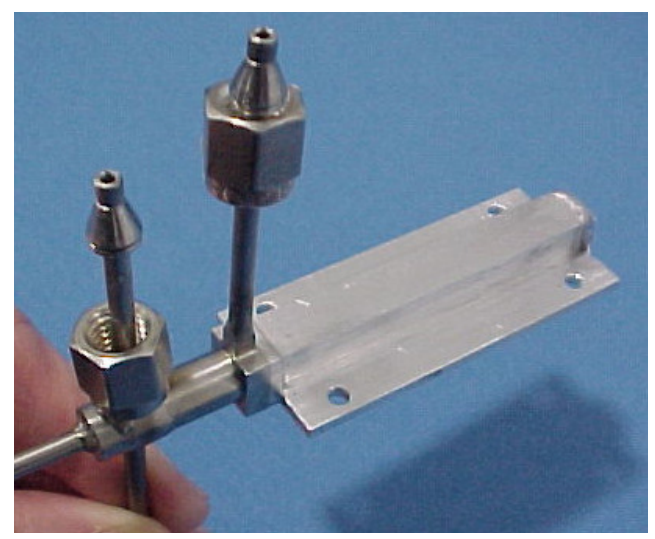

Fig. 2 Evaporator with a porous Teflon wick

\section{HLHPS MODELING GOALS AND APPROACH}

The configuration in the Thermal Desktop ${ }^{\mathrm{TM}}$ image in Figure 4 is consistent with that in Figure 3 while additionally communicating that the HLHPS components can be tightly packaged into a specific system volume where the components can have different orientations and the transport lines can be shaped in any way to comply with the application. Gravity effects on the pressure distribution are accounted for by the model.

Following the modeling approach pioneered by Cullimore and Bauman (2000), which was also utilized by Khrustalev (2010a), the modeling philosophy used herein is to represent the HLHPS components with a minimal amount of details, which is still sufficient to capture transients in temperatures, pressures, mass flow rates, and flow qualities across the HLHPS. Consequent analysis of the model predictions leads to a better understanding of the thermal-fluid mechanisms that limit the HLHPS performance envelope. Some details of the modeling technique are discussed below.

Figure 5 illustrates a simple but adequate approach to modeling HLHPS components such as reservoir, capillary evaporator, and condenser. Fluid lumps and solid nodes essential for the model can be seen in the figure and are explained below. Fluid lump FF2701 is a two-phase "tank" representing the reservoir with an internal volume of $115 \mathrm{~cm}^{3}$. Its quality varies in time depending on the mass of fluid contained in the condenser; however this "tank" always has both saturated vapor and liquid inside it, due to the design intent. The "tank" receives either single-phase liquid or two-phase fluid coming out of the subcooler through a "path" from the liquid return fluid lump FF1446. This fluid lump is thermally tied to node LP1 representing cylindrical surface and metal wall of the reservoir, which can be radiatively exchanging thermal energy with a heat sink or environment. An "arithmetic" (zero heat capacity) node LP55 linked to node LP1 is added for convenience and is programmed to read the instant heat flow rate on the reservoir. Node LP55 is also used to apply a minor heat load to the reservoir in order to keep it at a desired temperature level. Node LP1 is shown with a conductor leading to the condenser plate, which represents a thermal strap between the reservoir and condenser plate (visible in Figure 3), however the value of this conductor was conveniently set to be zero for the modeling results presented in this paper.

Fluid lump FF2701 serves as the liquid supply for the Thermal Desktop $^{\mathrm{TM}}$ macro CAPPMP representing the secondary capillary evaporator. Fluid lump FF2709 is the vapor-generating part of the
CAPPMP evaporator and LP2 is the vapor saturation temperature node on the evaporator side. Lump FF2701 is linked to the evaporator "saturation temperature" node LP2 via a thermal "tie" FF2502. Thermal conductance of this tie is adjusted in "Variables 1" at each time step of the transient solution to maintain the proper value of the heat leak flow rate, $\boldsymbol{Q}_{\boldsymbol{B} C}$, which is defined by Equation (1) and explained below.

Heat loading of the evaporator outer surface generates vapor flow into the vapor transport line with the mass flow rate $\boldsymbol{m}_{\boldsymbol{v}}$ and simultaneously, some possible vaporization on the inner surface of the primary wick with the mass flow rate $\boldsymbol{m}_{B C}$ and corresponding vapor flow into the reservoir. This possible vapor flow into the reservoir is due to the heat leak flow rate through the cylindrical wall of the primary wick, which is called "back conduction" and is proportional to the temperature drop across the cylindrical wall of the primary wick. If the fluid in the inner evaporator core is two-phase, the temperature drop is calculated in the model based on the pressure drop between the saturation vapor pressure inside the axial grooves on the outer surface of the primary wick and the saturation vapor pressure inside the twophase reservoir. This pressure drop, $\boldsymbol{\Delta} \boldsymbol{P}_{\boldsymbol{V}-\boldsymbol{R}}$, is due to the viscous vapor and liquid flow through the transport lines and all other fluid passages as well as the liquid head in the field of gravity. Note that $\boldsymbol{\Delta} \boldsymbol{P}_{\boldsymbol{V}-\boldsymbol{R}}$ does not include the viscous pressure drop for the liquid filtering through the porous walls of the primary wick from the inner surface to the outer surface were vapor generation takes place. Thus the main component of the "back conduction" heat flow rate, $\boldsymbol{Q}_{\boldsymbol{B} C}$, between the evaporator and the reservoir is based on the pressure drop between these two components, $\boldsymbol{\Delta} \boldsymbol{P}_{\boldsymbol{V}-\boldsymbol{R}}$, and depends on the steepness of the saturation curve, $\boldsymbol{d P} / \boldsymbol{d} \boldsymbol{T}_{\text {sat }}$, as expressed by Equation (1):

$$
\begin{aligned}
& Q_{B C}=\left[1 / C_{\text {wick }}+1 /\left(\pi D_{i} L_{e} h\right)_{f}\right]^{-1} \Delta P_{V-R}\left(d P / d T_{\text {sat }}\right)^{-1} \\
& +C_{\text {wall }}\left(T_{\text {ev }}-T_{\text {res }}\right)
\end{aligned}
$$

Equation (1) includes the primary wick thermal conductance, $\boldsymbol{C}_{\text {wick }}$, as well as the term reflecting heat transfer from the inner (cylindrical) surface of the primary wick to the fluid flowing through the evaporator core, $\boldsymbol{h}_{\boldsymbol{f}}$. The highest value of the back conduction corresponds to the situation with the vapor (two-phase fluid) filling most of the evaporator inner core where the heat transfer coefficient characterizing evaporation of the working fluid from the inner surface of the primary wick is relatively high. The lowest possible value of the back conduction is for the situation with the subcooled (or slightly superheated) single-phase liquid filling the inner evaporator core, where the heat transfer coefficient between the single-phase liquid and the inner surface of the primary wick is relatively low. The last term in Equation (1), which usually can be neglected in comparison with the first term, is related to the conductance of the metal connector, $\boldsymbol{C}_{\boldsymbol{w} \text { all }}$, welded to the reservoir on one end and to the evaporator on the other end. If the major term in Eq. (1) is based on the pressure drop rather than on the temperature drop, accounting for the back conduction in a Thermal Desktop ${ }^{\mathrm{TM}}$ model involves some additional programming. The primary wick thermal conductance, $\boldsymbol{C}_{\text {wick }}$, is not exactly a constant, since it can be affected by the liquid flowing through the porous structure from the inner surface of the primary wick to its outer surface. However, for the purpose of the presented HLHPS model, $\boldsymbol{C}_{\text {wick }}$, is assumed to be a constant defined purely by conduction in the porous material. 


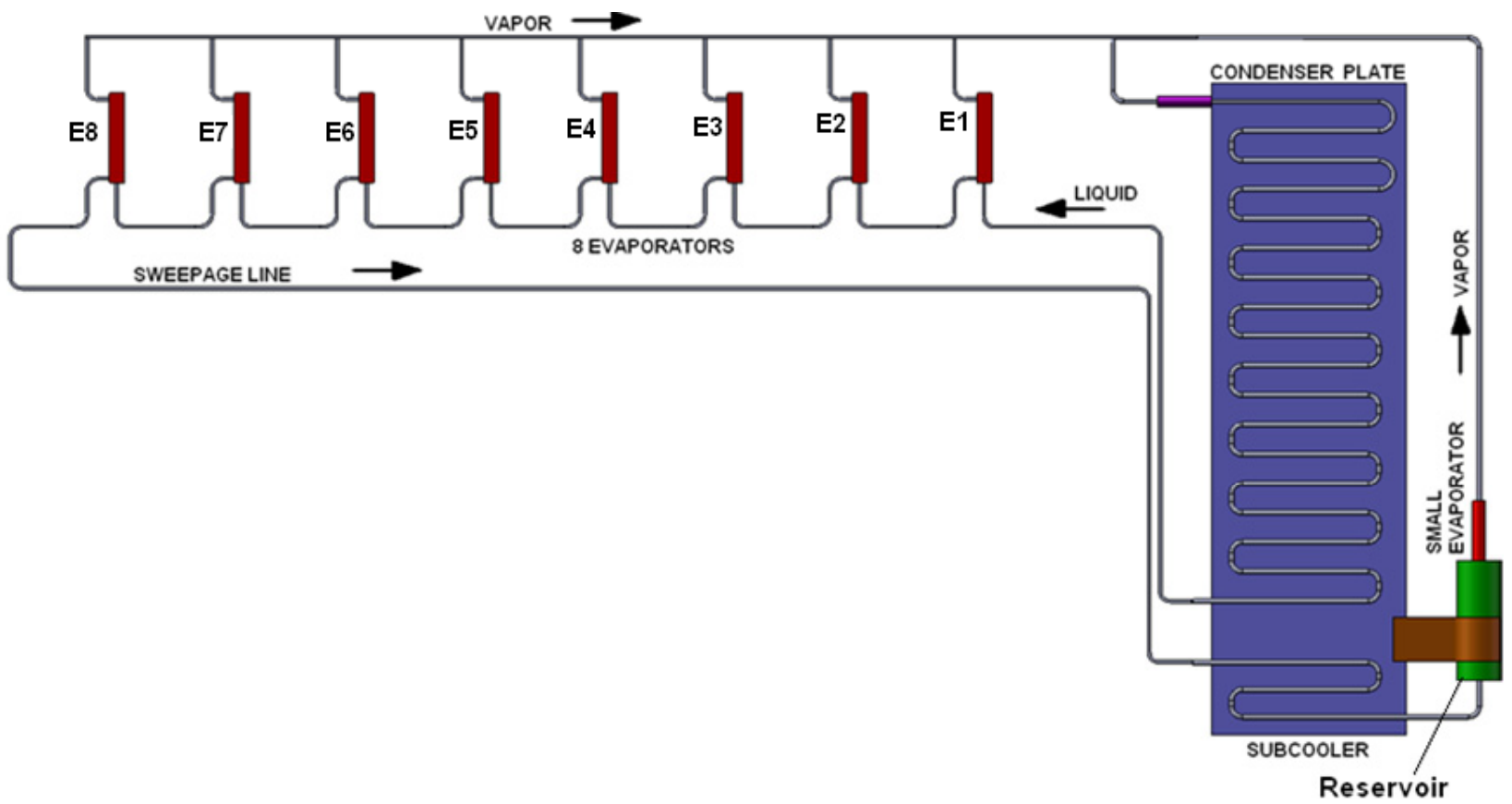

Fig. 3 CAD image of a HLHPS with eight main in-series evaporators

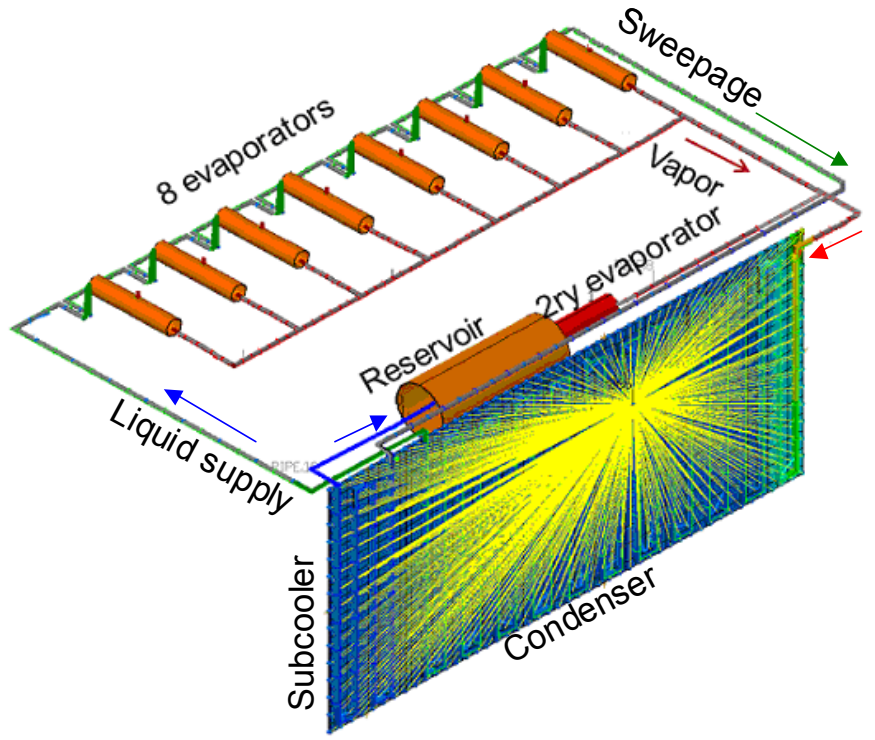

Fig. 4 Thermal Desktop ${ }^{\mathrm{TM}}$ model of the HLHPS

If the fluid in the evaporator core is single-phase, the back conduction heat flow rate in Eq. 1 is based on the temperature difference between the saturated vapor in the evaporator and the reservoir. Such description of the back conduction is sufficient for the HLHPS model described in this paper due to the two reasons: (1) the reservoir is temperature controlled by applying a small portioned heat load to its wall, where the exact value of this heat load is not important for the qualitative predictions, and (2) back conduction in the main evaporators is very low due to low conductivity of the porous Teflon and large thermal resistance associated with the term reflecting convective heat transfer from the inner (cylindrical) surface of the primary wick to the singlephase liquid inside the evaporator core, $\boldsymbol{h}_{\boldsymbol{f}}$. The evaporator saturation node LP2 is linked through a conductor to the evaporator wall node LP10, which represents the heat capacity and mass-averaged temperature of the evaporator cylindrical body and evaporator plate. The conductor between these two nodes is assigned a conductance value equal to the experimental value of the evaporator thermal conductance. Fluid lump FF2709 stands for the vapor volume of the axial grooves in the evaporator. Fluid path FF1112 has a "duplication factor" equal to the number of the axial grooves in the evaporator and leads the vapor generated by the evaporator to the vapor transport line. As soon as a heat load is applied to the evaporator wall (node LP10) and two-phase conditions exist, vapor is generated in the fluid lump FF2709 with the mass flow rate equal to the consumption of liquid coming out of the reservoir (fluid lump FF2701) into the evaporator. This phase change process is modeled using CAPPMP macro available in Thermal Desktop ${ }^{\mathrm{TM}}$, which does not have graphic visibility in Figure 5. The secondary wick is not explicitly present in this model, since it is assumed that its design guarantees the supply of sufficient liquid to the primary wick under any transient conditions, while the secondary evaporator heat load is kept at a relatively low level. Thermal Desktop $^{\mathrm{TM}}$ (Sinda/Fluint) LHP model shown in Figures 4 and 5 simulate transient circulation of the two-phase working fluid in the LHP components (condenser, evaporators, reservoir, and transport lines) and the temperature distribution across the LHP components including the condenser plate and subcooler. There are typically more than 500 fluid lumps (and also 500 corresponding nodes, paths, and ties) in a LHP model in order to present the condenser lines and other components in sufficient detail. The flow quality for each fluid lump is calculated by Sinda/Fluint based on the pressures, temperatures, and lump energy balance. The condenser and subcooler tubing ("pipes with walls") is bonded to the condenser plate using "contactors" accounting for the temperature drop corresponding to the bond design and material. The outlet end of the condenser tubing is typically filled with the liquid subcooled below the saturation temperature, while the beginning of the condenser tubing contains both vapor and liquid (condensate) phases. The total fluid mass contained in the condenser varies in time under transient regimes as well as the fluid mass in the reservoir. 


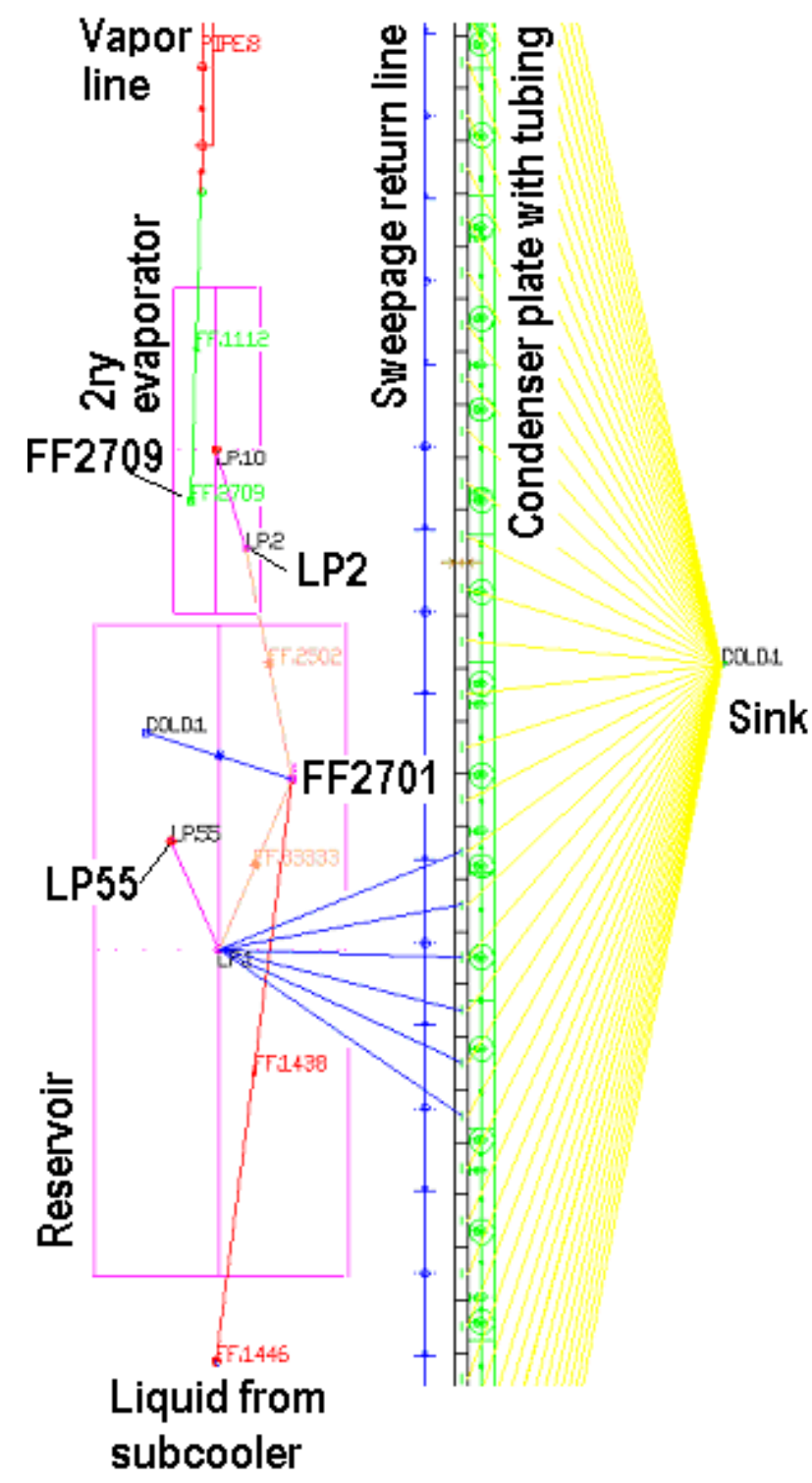

Fig. 5 Fragment of the HLHPS model with Reservoir, secondary evaporator and condenser

The reservoir heat capacity is thus dependent on the current fluid distribution between the HLHPS components and is found as a result of solving the mass conservation equations by the model. The HLHPS model simultaneously solves the flow momentum, energy, and mass conservation equations for the two-phase and single-phase fluid flow for each fluid lump and path separately as well as for the entire fluid submodel. It includes all three heat transfer mechanisms: convective, conductive (conduction in the condenser plate and subcooler plate), and radiative (radiation to the heat sinks), and also accounts for the phase change heat transfer. Since ThermalDesktop ${ }^{\mathrm{TM}}$ package includes a thorough description of the conservation equations used to describe two-phase systems with all heat transfer mechanisms, these equations are not repeated in this paper.

The modeled HLHPS parameters are summarized in Tables 1 through 3. The modeled HLHPS is of the same scale that the ST- 8 system described by Bugby (2007) and also uses porous Teflon as the primary wick material.
Table 1 Parameters of the eight main evaporators

\begin{tabular}{|c|c|c|c|c|}
\hline Component & $\begin{array}{c}\text { Conductance } \\
(\mathrm{W} / \mathrm{K})\end{array}$ & $\begin{array}{c}\text { Back } \\
\text { conductance } \\
(\mathrm{W} / \mathrm{K})\end{array}$ & $\begin{array}{c}\text { Heat } \\
\text { capacity } \\
(\mathrm{J} / \mathrm{K})\end{array}$ & $\begin{array}{c}\text { Heat } \\
\text { load } \\
(\mathrm{W})\end{array}$ \\
\hline Evaporator 1 & 20 & 0.04 & 150 & 100 \\
\hline Evaporator 2 & 30 & 0.06 & 200 & 100 \\
\hline Evaporator 3 & 30 & 0.06 & 200 & 100 \\
\hline Evaporator 4 & 20 & 0.04 & 150 & 100 \\
\hline Evaporator 5 & 20 & 0.04 & 150 & 100 \\
\hline Evaporator 6 & 30 & 0.06 & 200 & 100 \\
\hline Evaporator 7 & 30 & 0.06 & 200 & 100 \\
\hline Evaporator 8 & 20 & 0.04 & 150 & 100 \\
\hline
\end{tabular}

Table 2 Parameters of the major fluid lines

\begin{tabular}{|l|l|l|l|l|}
\hline \multicolumn{1}{|c|}{$\begin{array}{c}\text { Component } \\
\text { tubing }\end{array}$} & $\begin{array}{c}\text { Inner } \\
\text { diameter } \\
(\mathrm{mm})\end{array}$ & $\begin{array}{c}\text { Wall } \\
\text { thickness } \\
(\mathrm{mm})\end{array}$ & $\begin{array}{c}\text { Typical } \\
\text { length } \\
(\mathrm{m})\end{array}$ & $\begin{array}{c}\text { Wall } \\
\text { material }\end{array}$ \\
\hline Condenser & 2.95 & 0.5 & 3.94 & $\mathrm{SS} 304$ \\
\hline Vapor transport & 2.95 & 0.5 & 0.64 & $\mathrm{SS} 304$ \\
\hline $\begin{array}{l}\text { Liquid return } \\
\text { transport }\end{array}$ & 2.95 & 0.5 & 0.64 & $\mathrm{SS} 304$ \\
\hline $\begin{array}{l}\text { Sweepage } \\
\text { transport }\end{array}$ & 2.95 & 0.5 & 0.64 & $\mathrm{SS} 304$ \\
\hline Subcooler & 2.95 & 0.5 & 0.71 & $\mathrm{SS} 304$ \\
\hline
\end{tabular}

Table 3 Other relevant modeled HLHPS parameters

\begin{tabular}{|l|c|}
\hline \multicolumn{1}{|c|}{ Component parameter } & Parameter value \\
\hline Reservoir volume & $115 \mathrm{~cm}^{3}$ \\
\hline Reservoir wall heat capacity & $100 \mathrm{~J} / \mathrm{K}$ \\
\hline Secondary evaporator conductance & $53 \mathrm{~W} / \mathrm{K}$ \\
\hline Secondary evaporator heat capacity & $45 \mathrm{~J} / \mathrm{K}$ \\
\hline $\begin{array}{l}\text { Condenser plate dimensions }(\mathrm{mm}) \text { and } \\
\text { material }\end{array}$ & $178 \times 305 \times 2 \mathrm{Al6063}$ \\
\hline $\begin{array}{l}\text { Subcooler plate dimensions }(\mathrm{mm}) \text { and } \\
\text { material }\end{array}$ & $178 \times 61 \times 2 \mathrm{Al} 6063$ \\
\hline $\begin{array}{l}\text { Contact from the condenser/subcooler } \\
\text { plate to the sink }\end{array}$ & $250 \mathrm{~W} / \mathrm{K}$ \\
\hline $\begin{array}{l}\text { Contact from the condenser tubing to } \\
\text { the plate }\end{array}$ & $400 \mathrm{~W} / \mathrm{K}$ \\
\hline $\begin{array}{l}\text { Contact from the subcooler tubing to } \\
\text { the plate }\end{array}$ & $80 \mathrm{~W} / \mathrm{K}$ \\
\hline
\end{tabular}

Modeled transient case. One of the most severe transients for the HLHPS modeled is associated with the heat load on/off switching on the main evaporators. Each of the eight main evaporators is heat loaded with $100 \mathrm{~W}$ prior to the time of 4000 seconds as shown in Figure 6 . During the next 180 seconds the heat load on the main evaporators is gradually decreased to zero and there is no heat load on the main evaporators during the time interval from 4180 seconds to 5000 seconds. At the time of 5000 seconds all eight evaporators are heat loaded again with $100 \mathrm{~W}$ each. The secondary evaporator is continuously loaded with $90 \mathrm{~W}$. Since it is usually desirable to keep the 


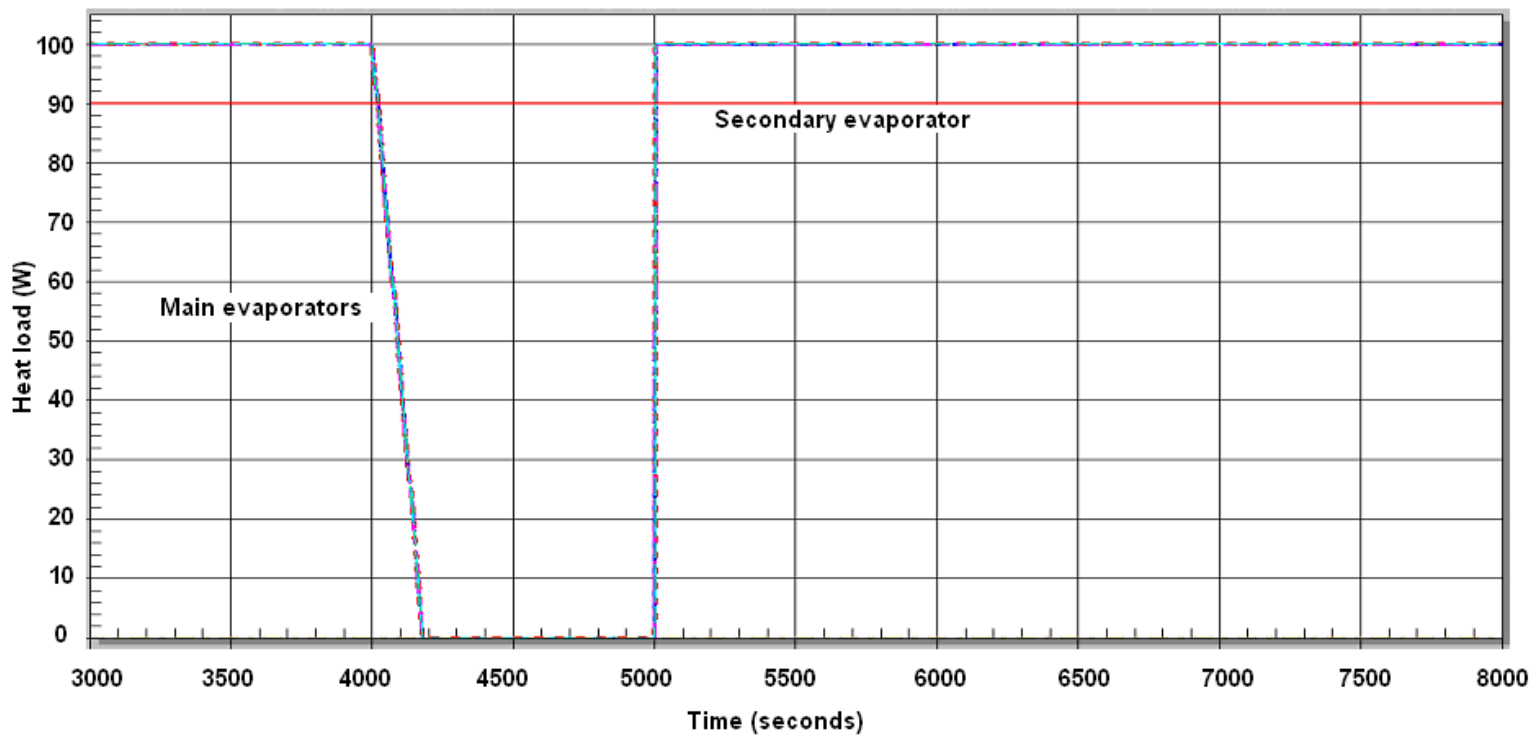

Fig. 6 Heat load variation on the main evaporators

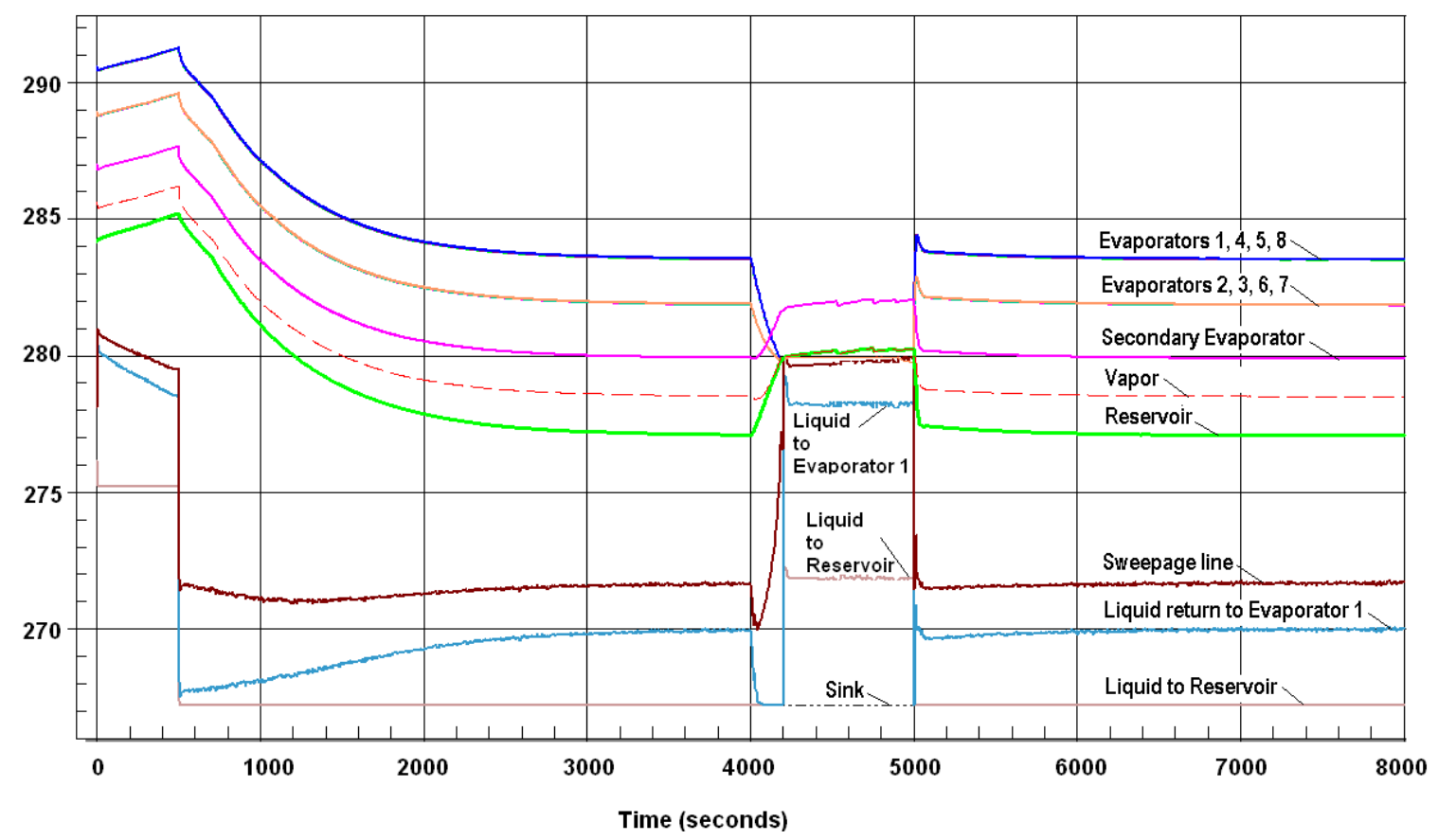

Fig. 7 Transient temperatures of the HLHPS components

heat sources cooled by the main evaporators in a relatively narrow temperature range, the reservoir is additionally heat loaded with $7 \mathrm{~W}$ during the 180 seconds time interval after 4000 seconds as will be additionally explained below. This reservoir heating elevates its temperature during the time period with the zero heat load in order to keep the main evaporators temperatures within several degrees from the full heat load level. Modeling results are discussed below.

\subsection{TEMPERATURE CONTROL AND MODELING RESULTS}

Figure 7 presents the predicted temperatures of the HLHPS components versus time. Nine top curves are for the heated wall temperatures of the nine evaporators (including the secondary one). The remaining temperature curves are for the following model components: reservoir, heat sink, temperature of liquid coming out of the condenser, temperature of liquid in the sweepage line after eight main evaporators, temperature of liquid coming into the reservoir from the subcooler (lump FF1446) and the vapor temperature at evaporator \#8.

After the initial resetting (at 500 seconds) of the sink temperature from $275.1 \mathrm{~K}$ to $267 \mathrm{~K}$ all temperatures become stabilized by 4000 seconds, at which time the heat load on the main evaporators is reduced to zero within 180 seconds although the secondary evaporator is continuously heat loaded with $90 \mathrm{~W}$. The main evaporators do not generate vapor during the time when the heat load is zero, however, due to the heat load on the secondary evaporator, the liquid keeps flowing through their inner cores cooling them and the outer surfaces of the primary wicks are exposed to the vapor 
generated by the secondary evaporator. In order to keep the main evaporators within $4 \mathrm{~K}$ of the stabilized temperature of $284 \mathrm{~K}$ a heat load of $7 \mathrm{~W}$ is applied to the reservoir during the time from 4000 seconds to 4180 seconds. Additionally, two small heat loads are applied to the liquid line coming out of the condenser $(3.2 \mathrm{~W})$ and liquid line coming out of the subcooler $(1.35 \mathrm{~W})$ during the time from 4200 seconds to 5000 seconds. These two small heat loads warm up the cold liquid entering evaporator \#1 and reservoir so that temperatures of these components do not decrease during the zero heat load time. In fact, all temperatures are practically stabilized by the time of 5000 seconds, when the heat load is re-applied to the eight main evaporators ( $100 \mathrm{~W}$ per evaporator). Heat loading the eight main evaporators at 5000 seconds elevates their temperatures from $280 \mathrm{~K}$ to $284 \mathrm{~K}$ while simultaneously reduces the reservoir temperature to $277.5 \mathrm{~K}$ as discussed below.

Figure 8 provides the combined heat flow rate on the reservoir due to the external heat load and the "condenser discharge cooling effect" at 5000 seconds. Note that the reservoir is heat loaded with $2.5 \mathrm{~W}$ most of the time, except for 180 seconds after the time of 4000 seconds when the heat load is increased to $7 \mathrm{~W}$. The "condenser discharge cooling effect" deserves a closer consideration, since it is responsible for cooling down the reservoir by $2.5 \mathrm{~K}$ within 20 seconds or so after the heat loads are re-applied to the main evaporators at 5000 seconds. As clearly seen in Figure 9 the condenser is mostly filled with cold liquid ammonia prior to 5000 seconds, since the vapor mass flow rate into the condenser corresponds to only $90 \mathrm{~W}$ on the secondary evaporator. After applying $800 \mathrm{~W}$ to the main evaporators at 5000 seconds the vapor is entering and filling most of the condenser (see Figure 10), forcing the liquid out of it into the reservoir through the sweepage line and subcooler. Since the subcooler liquid is colder than the reservoir, it cools reservoir with the heat flow rate corresponding to the temperature difference between these two components:

$$
Q_{\text {cooling }}=\left(d M_{\text {cond }} / d t\right) c_{p}\left(T_{\text {res }}-T_{\text {subcooler }}\right)
$$

where $M_{\text {cond }}$ is mass of the working fluid in the condenser at time $t$. Note that the reservoir heat capacity is increasing in the process of acquiring liquid coming out of the condenser. The fluid flow quality in the condenser is gradually changing from 1 (saturated vapor) to 0 (single-phase liquid) along the condenser tubing as presented by Figure 11 where the flow quality at eleven bends (locations from right to left in Figure 10) is plotted versus time. Figure 11 provides some idea how the condenser is being filled with liquid during 180 seconds after 4000 seconds, which is then displaced by vapor after 5000 seconds. It is partially due to the condenser discharge cooling effect that there is no temperature overshoot on the main evaporators during the heat load application at 5000 seconds.

The main point of the temperature control of the HLHPS is to reduce the temperature variation on the main evaporators so that sensitive electronic components cooled by these evaporators do not experience significant temperature gradients. Due to the steps where small heat loads were applied to the reservoir and liquid return lines, the main evaporators stayed within the temperature band of $4.5 \mathrm{~K}$ during the heat load on/off/on event, where the lowest evaporator temperature was $279.5 \mathrm{~K}$. Without applying these small heat loads, the first evaporator temperature with time could have dropped close to that of the sink $(267 \mathrm{~K})$, since the cold liquid pumped by the secondary evaporator is continuously flowing through the evaporator's inner cores.

A closer look at the evaporators temperature variation is provided by Figure 12. Since there are only two types of the main evaporators used in the model and the heat loads between them are fairly similar, there are two types of the temperature curves. When heat loaded, evaporators $2,3,6$, and 7 are at a higher temperature level than the others due to the higher ratio of the applied heat load to their conductance value in Table 1. All evaporators are at the same temperature level during the zero heat load time, since the liquid flowing through their inner cores is pre-heated, which further reduces the heat leak through the primary wicks. This liquid pre-heating was not utilized during the last 40 seconds of the zero heat load time period, which resulted in the evaporator temperatures gradually reducing prior to the time of 5000 seconds as can be seen in Figure 12.

Finally, the pressures of several HLHPs components are plotted versus time in Figure 13. The largest pressure drop of about 20,000 $\mathrm{Pa}$ is due to the fluid flow through the condenser at the time when the total heat load of $890 \mathrm{~W}$ is applied to the HLHPS. The vapor lines are

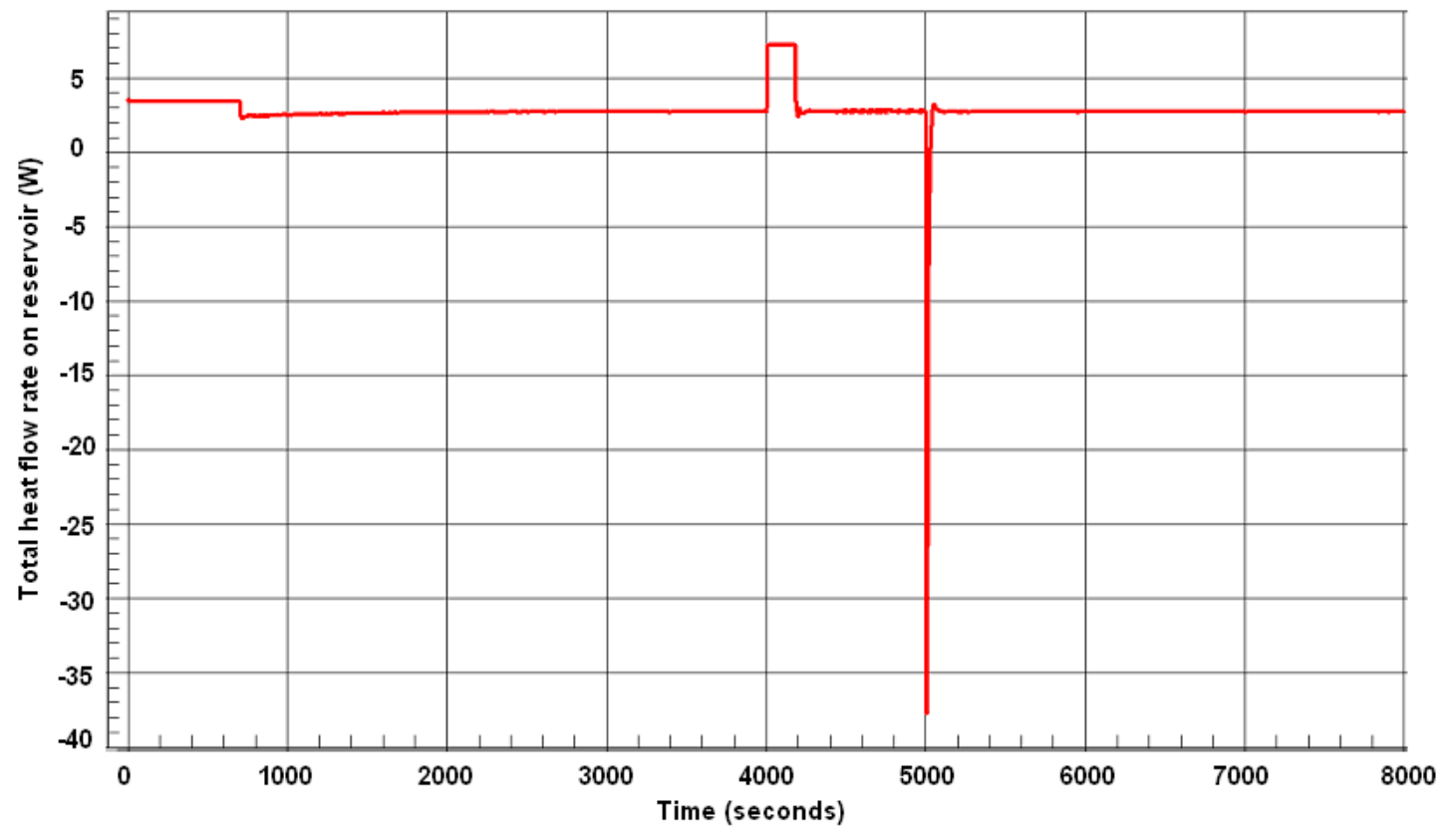

Fig. 8 Total heat flow rate on the reservoir due to the external heat loading and condenser discharge cooling 
much shorter than the condenser and therefore do not create high pressure drops. The absolute pressure is elevated during the zero heat load time period due to the heat load of $7 \mathrm{~W}$ applied to the reservoir. The pressure drops between the components are very small in the absence of the major heat load. One additional pressure drop is the viscous pressure drop due to the liquid filtering through the primary wick from its inner surface to its outer surface (not shown in Figure 13). The total sum of the pressure drops in the HLHPS should be lower than the capillary potential of the primary wick at all times for the HLHP to work within its design parameters envelope. This is actually one of the bounding limitations for HLHPS, which serves as the basis for HLHPS thermal/fluid design. This capillary potential limitation as well as other performance limitations should be carefully explored during HLHPS thermal-fluid design using the modeling tool described herein. This assures the HLHPS is operating within its reliable parameters envelope while meeting the system requirements.

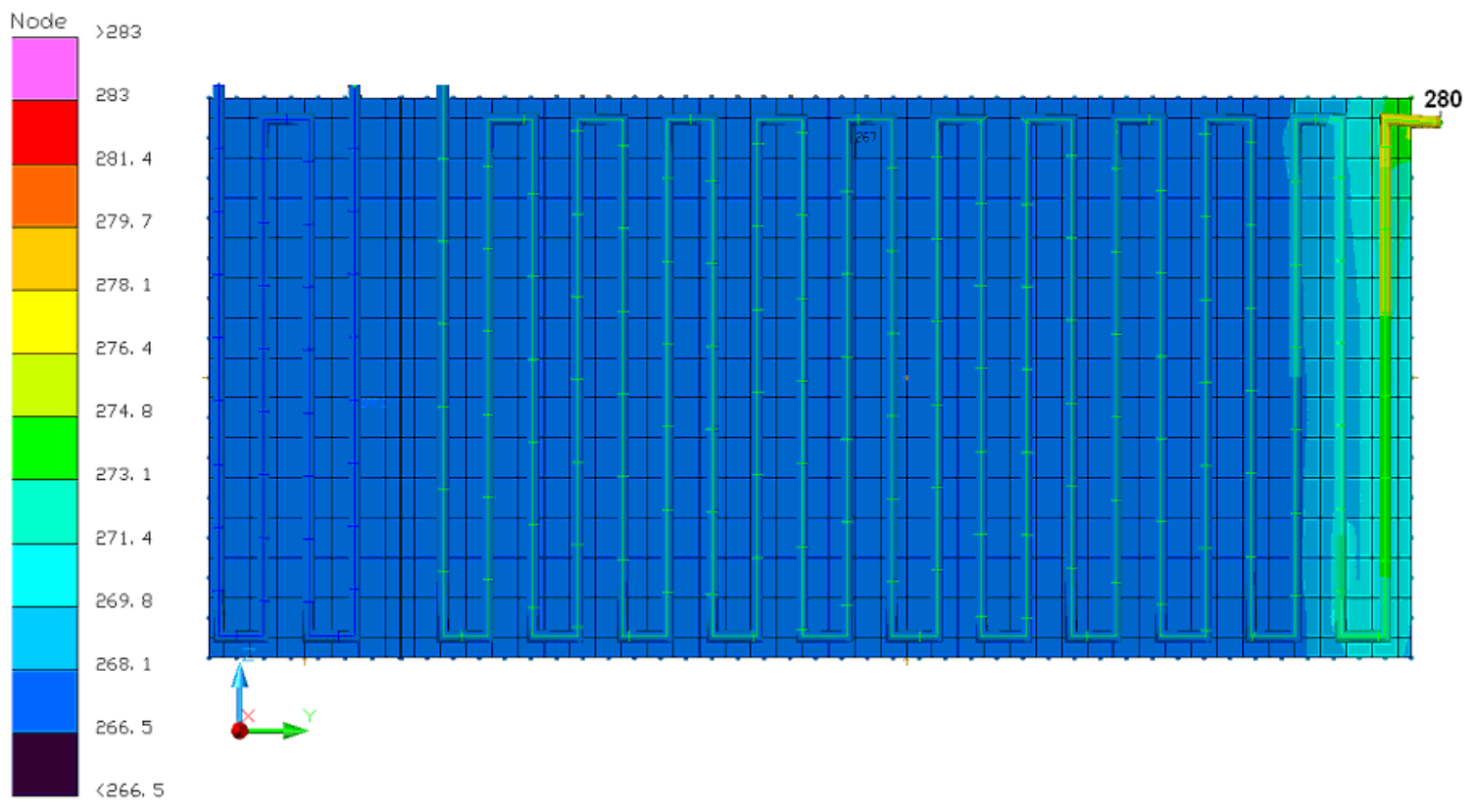

Temperature $[\mathrm{K}]$, Time $=4500 \mathrm{sec}$

Fig. 9 Temperature distribution on the condenser/subcooler plate at 4500 seconds
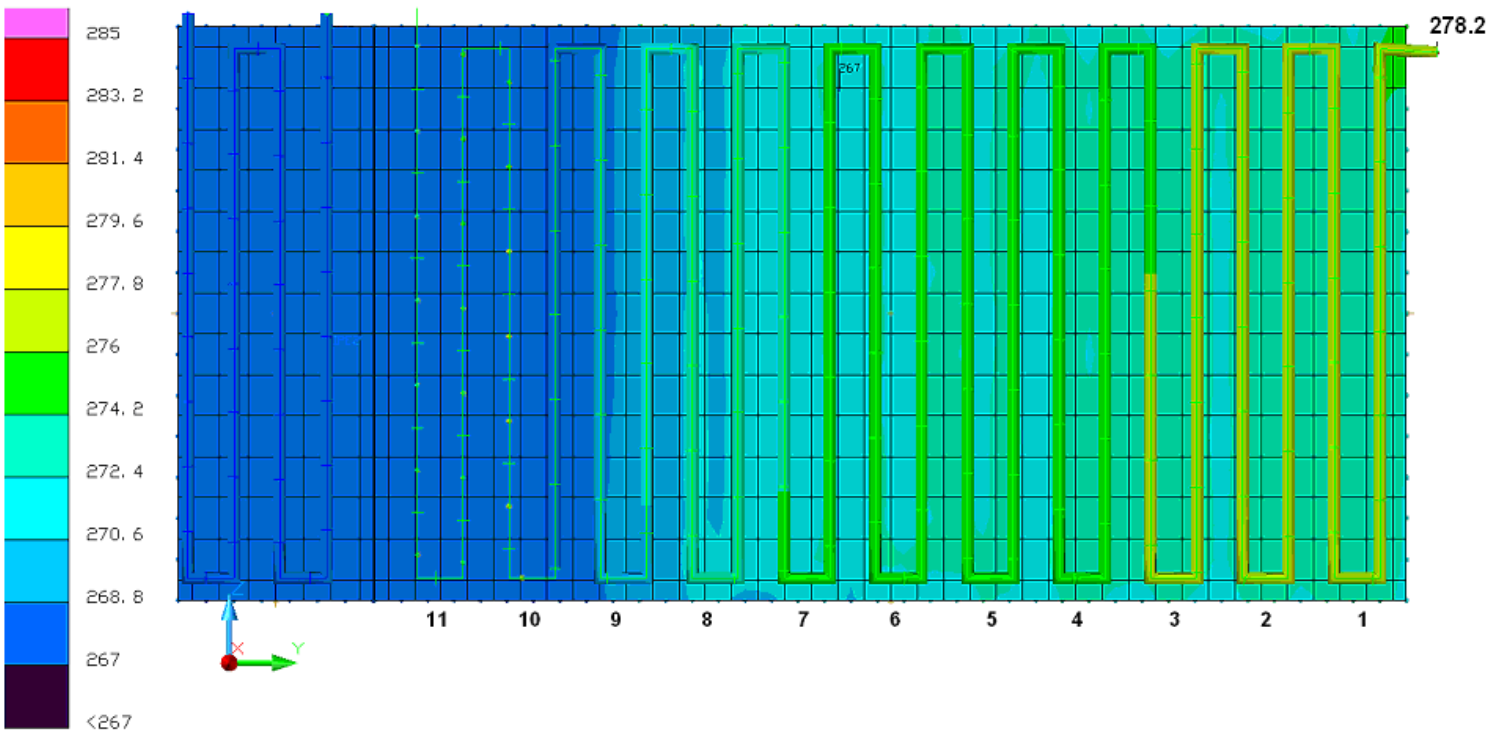

Temperature $[K]$, Time $=7000 \mathrm{sec}$

Fig. 10 Temperature distribution on the condenser/subcooler plate at 7000 seconds 


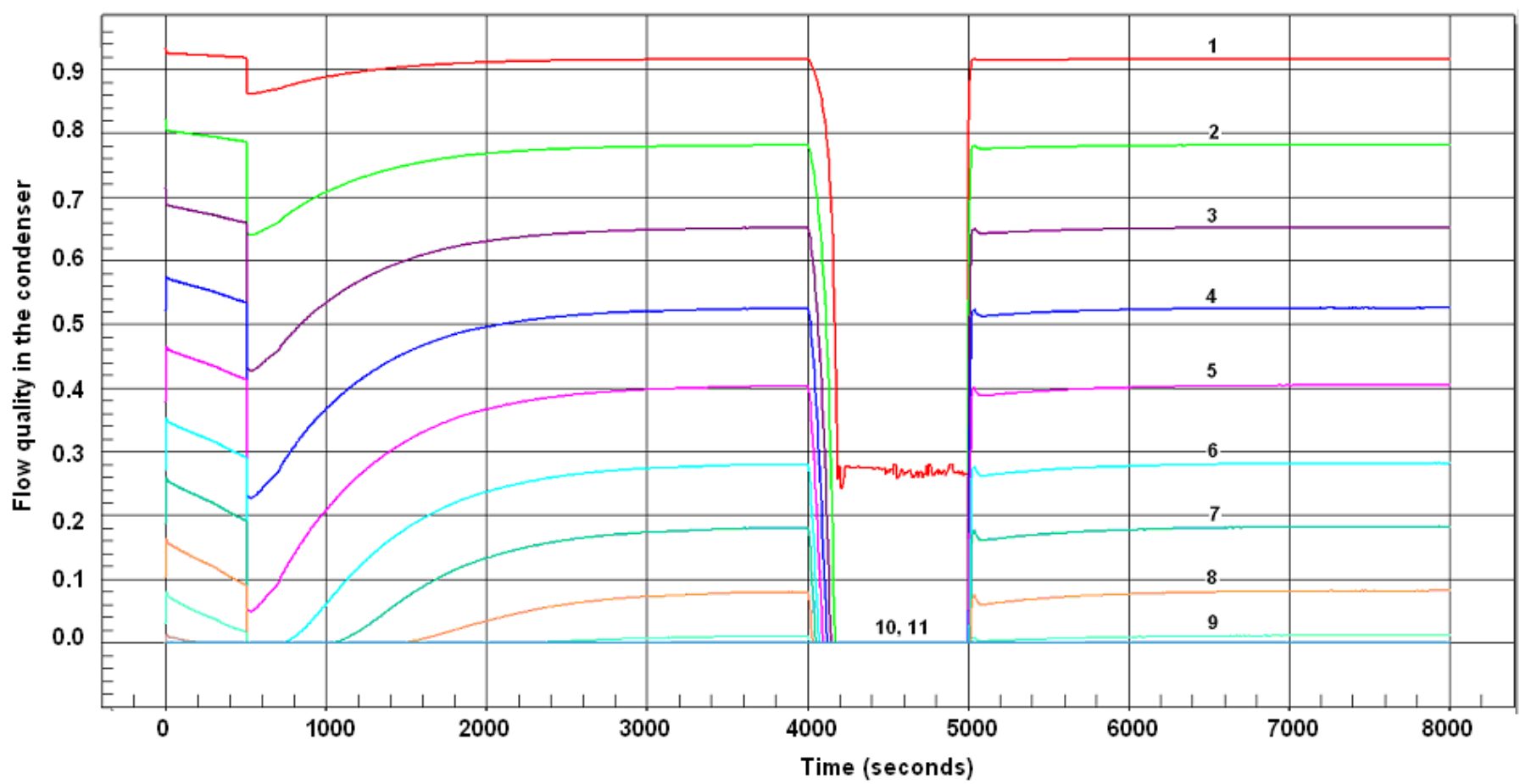

Fig. 11 Flow quality at eleven locations in the condenser (see Figure 10) versus time

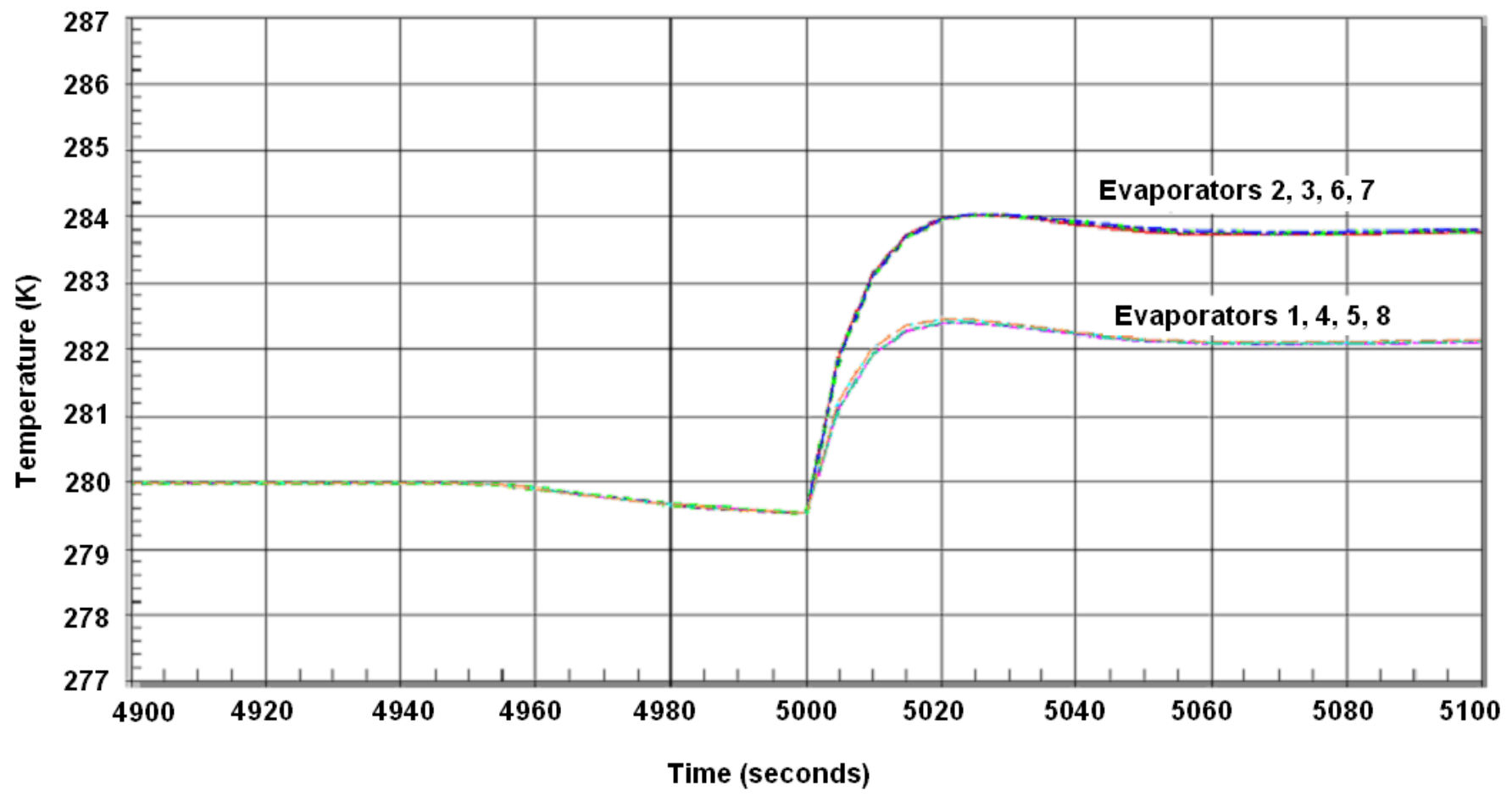

Fig. 12 Temperature variation on the main evaporators versus time 


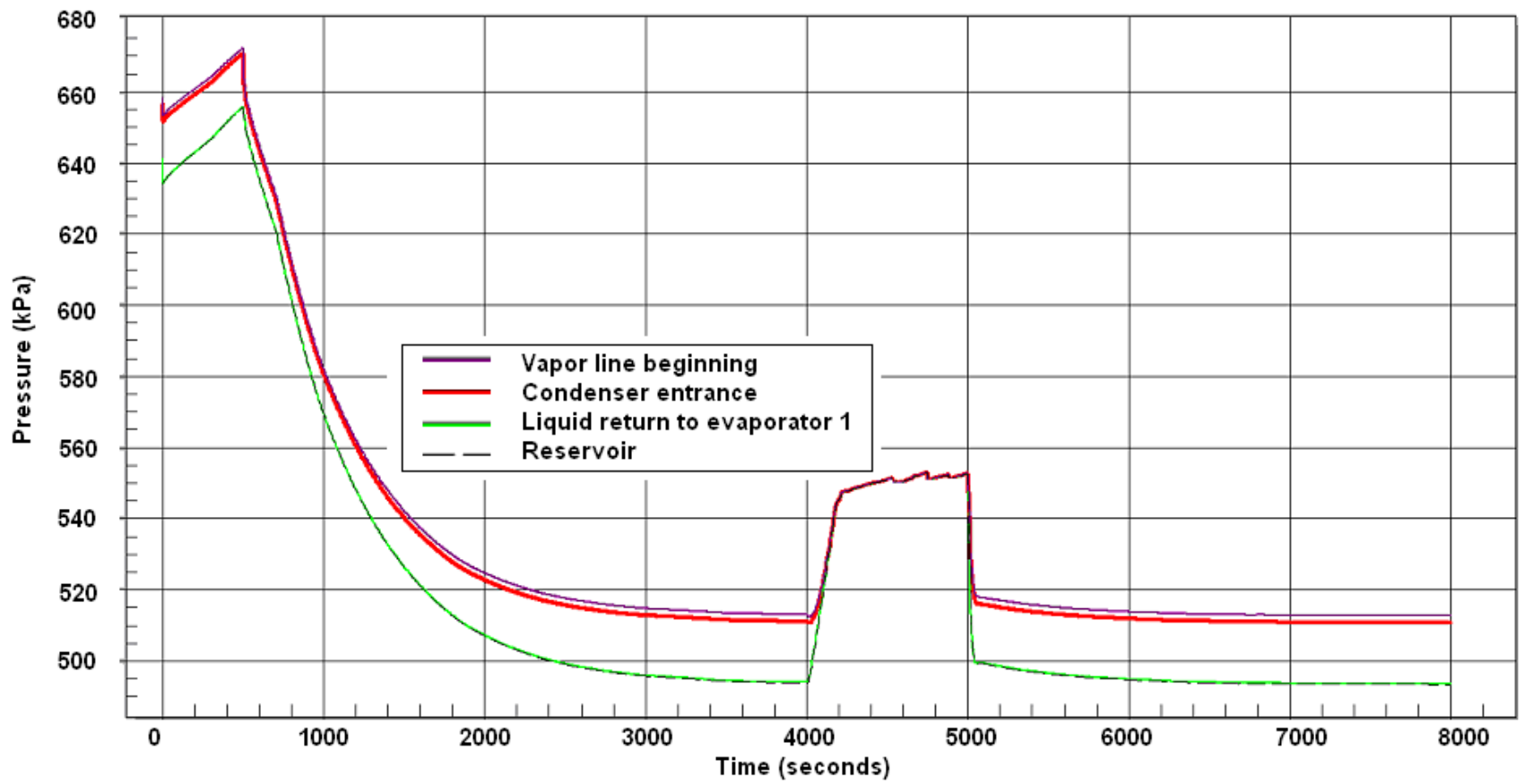

Fig. 13 Pressure variation in HLHPS components versus time

\subsection{SUMMARY AND CONCLUSIONS}

Transient modeling of HLHPSs presented in this paper is a tool to custom-design such systems for reliable performance under transient conditions. HLHPSs are more versatile than LHPs and also scalable up to 100 kilowatts, due to their modular thermal-fluid architecture where the number of the main evaporators can be increased correspondingly. Therefore HLHPs should be appropriately modeled at the thermal design stage to make sure they can withstand severe transients due to the power variations typical for some applications. The main points of the paper are summarized below.

1. A simple Sinda-Fluint model using Thermal Desktop ${ }^{\mathrm{TM}}$ platform has been developed to describe thermal-fluid transients in a HLHPS with eight primary and one secondary evaporator during the heat load on/off/on event, which is perhaps the most severe transient for HLHPs. Such a model is a necessary tool for HLHPS thermal-fluid design to ensure its reliable operation under the transient conditions and requirements specified by the application.

2. A temperature control approach utilized in the model above is aimed at minimizing temperature fluctuations on the main evaporators during the heat load on/off/on event and includes applying small heat loads to the reservoir and liquid return lines during the time when the heat load on the main evaporators is zero in order to keep their temperatures from gradually dropping down to the sink temperature.

3. Continuous portioning of a small heat load applied to the reservoir keeps the liquid coming out of the condenser at single-phase conditions and prevents vapor from flowing through the condenser and into the main evaporator cores, which could otherwise potentially result in some instabilities in the HLHPS operation.

4. Modeling results show that discharge of cold liquid out of the condenser and into the reservoir at the time when the heat load is re-applied to the main evaporators produces a significant cooling effect on the reservoir, which should be accounted for during the thermal-fluid design. No additional reservoir cooling means was necessary for the modeled HLHPS, however generally the reservoir energy balance is an important consideration for any particular HLHPS application.

\section{ACKNOWLEDGEMENTS}

Authors acknowledge Mr. Dave Wolf for providing valuable comments pertaining to the operational principles of HLHPs.

\section{NOMENCLATURE}

C conductance $(\mathrm{W} / \mathrm{K})$

$\mathrm{c}_{\mathrm{p}} \quad$ specific heat $(\mathrm{J} / \mathrm{kg}-\mathrm{K})$

$\mathrm{D} \quad$ diameter $(\mathrm{m})$

FF fluid submodel name

h heat transfer coefficient $\left(\mathrm{W} / \mathrm{m}^{2}-\mathrm{K}\right)$

L length (m)

LP node submodel name

$\mathrm{m} \quad$ mass flow rate $(\mathrm{kg} / \mathrm{s})$

M mass of the fluid in the condenser $(\mathrm{kg})$

$\mathrm{P} \quad$ pressure $(\mathrm{Pa})$

$\triangle \mathrm{P} \quad$ pressure drop $(\mathrm{Pa})$

Q heat flow rate (W)

$\mathrm{T}$ temperature (K)

$\mathrm{t}$ time (seconds)

$\mathrm{X} \quad$ flow quality

Subscripts

BC back conduction

cond condenser

ev evaporator

fluid working fluid

L liquid

res reservoir

sat saturation

V-R vapor path from the vapor in the evaporator to the reservoir

wick primary wick

wall wall of the connector to the reservoir 


$\begin{array}{ll}\text { Acronyms } & \\ \text { HLHPS } & \text { Hybrid Loop Heat Pipe System } \\ \text { LHP } & \text { Loop Heat Pipe } \\ \text { CPL } & \text { Capillary Pumped loop }\end{array}$

\section{REFERENCES}

Bugby, D.C., 2007, "Multi-Evaporator Hybrid Two-Phase Loop Cooling System for Small Satellites" Proceedings of Small Satellite Conference, Space Dynamics Laboratory, Logan, Utah.

Cullimore, B., and Bauman, J., 2000, "Steady State and Transient Loop Heat Pipe Modeling," Proceedings of the 34th International Conference on Environmental Systems, "' (ICES), SAE 2000-01-2316.

Khrustalev, D., 2010a, "Advances in Transient Modeling of Loop Heat Pipe Systems with Multiple Components," Proceedings of Space, Propulsion \& Energy Sciences International Forum (SPESIF) 2010, Laurel, MD, Applied Physics Laboratory, March 1820,2010

Khrustalev, D., Cologer, P., and Wolf, D., 2008, "Mechanically Pumped Two-Phase System With Multiple Compact Evaporators
"Solid State Diode Laser Technology Review", DEPS, Albuquerque, New Mexico 2-5 June 2008.

Khrustalev, D., et al., 2010b, "Evaporator for Use in a Heat Transfer System," US Patent 7,661,464, Washington, D.C.: US Patent and Trademark Office.

Kroliczek, E., Yun, J., and Wolf, D., 2005, "Phase Control in the Capillary Evaporators," US Patent 6,889,754, Washington, D.C.: US Patent and Trademark Office.

Kroliczek, E., and Yun, J., 2006, "Heat Transfer System," US Patent 7,004,240, Washington, D.C.: US Patent and Trademark Office.

Wrenn, K., and Wolf, D., 2008, "Test Results for a High Power Thermal Management System", Proceedings of the 38th International Conference on Environmental Systems," (ICES), SanFrancisco, CA, SAE paper 2008-01-1997.

\section{PUBLIC RELEASE NOTE}

Approved for public release by Dept. of Defense, Office of Security Review 10-S-2566, July 12, 2010. 